\title{
APPLICABILITY OF AIR POLLUTION MODELING IN A CLUSTER OF BRICKFIELDS IN BANGLADESH
}

\author{
S. Ahmed ${ }^{1}$ and I. Hossain ${ }^{2 *}$ \\ ${ }^{I}$ Department of Chemical and Biomolecular Engineering, North Carolina State University, Raleigh, NC, USA. \\ ${ }^{2}$ Department of Chemical Engineering, Bangladesh University of Engineering \& Technology, Dhaka-1000, Bangladesh
}

Received 7 June 2008; received in revised form 15 July 2008

\begin{abstract}
Air pollution is one of the major environmental problems now days, especially for developing countries such as Bangladesh and Brickfields have been identified as a vital pollutant source of the major cities of the country. Verification of the applicability of an effective air quality model in Bangladesh condition, especially for brickfield pollution was the main concern of this work. To achieve that objective, ambient pollutant concentrations were measured experimentally and compared with the results generated through modeling using Industrial Source Complex (ISC3) model. Air sampling was done at different locations in a cluster of brickfields of 41 brick kilns near Amin Bazar, Savar using Gastec tubes and High volume sampler. Gastec tubes were used for gaseous pollutants and High volume sampler was used for Total Suspended Particulates (TSP). Gaseous pollutants included Sulfur dioxide, Carbon monoxide, and Hydrocarbons. Those pollutant data at different locations on different days were compared with simulated value generated through ISC3. Industrial Source Complex (ISC3) model was found very effective and appropriate both for gaseous pollutants and particulate matter for brickfield pollution in Bangladesh and which indicates the prospect of utilizing this model for different condition and purposes in Bangladesh. From both the experimental and simulated data, particulate matter had been identified as the most important pollutant in that region which is urgently needed to be taken care of.
\end{abstract}

Keywords: Air pollution, Brickfield, Gaussian Plume, ISC, Modeling.

\section{INTRODUCTION}

Air pollution is one of the major manmade environmental problems that has recently gained importance among environmental issues in Bangladesh. Exposure to air pollution is the main environmental threat to human health in towns and cities. Numerous brick-making kilns operating in the dry season are one of the major sources of air pollution in cities. A significant factor is that brick kilns are usually clustered near big cites in different parts of Bangladesh. Therefore, the parts of the city in the immediate vicinity of the brick-field clusters have serious air pollution problems.

Air quality of Dhaka city is severely affected by the pollutants from hundreds of brickfields located at the entry points into the Dhaka city: Amin Bazar, Keraniganj, Fatulla, Pagla, Tongi, Ashulia. These kilns produce bricks using an old conventional process. Every year more than 20 lakh metric tonnes of low quality coal and 20 lakh metric tons of wood are burnt in these brick fields along with tires and rubber [1]. Only few fields use natural gas where it is available. The pollution is caused by the poor quality of fuel, improper design of chimneys and combustion chamber. Pollutants such as oxides of carbon, sulfur dioxide, oxides of nitrogen, volatile organic compounds and particulates are produced from the brickfields. Moreover even under well-controlled processes worldwide, 0.2 microgram toxic equivalents of dioxins and furans are emitted as byproduct into the air during the production of each ton of brick, which is very harmful for lives [2]. Brickfields also cause crop loss, corrosion of metallic objects and loss of soil fertility.

Even though brickfields are one of the major sources of air pollution in Dhaka city, most of the research activities regarding air pollution in Dhaka deal with vehicle and industrial pollutions. Department of Environment (DOE), Bangladesh Council of Scientific and Industrial Research (BCSIR) and Bangladesh Atomic Energy Centre (BAEC), Dhaka are the main organizations working on air pollution, but none of the organizations were studying brickfields earlier. Recently this issue is being taken into consideration seriously. By the implementation of the national court order 2003, stack height of brick kilns have now been increased to $120 \mathrm{ft}$. From some survey results, it has been seen that the air pollution near Dhaka city increases to a large extent during the dry season $[1,3]$. As brickfields are operated during the dry season, it is clear that brickfields have large contribution to the air pollution. 
Though Air quality modeling is a very effective tool to predict ambient pollution level and is used worldwide but it is a new concept in Bangladesh. Air pollution modeling has never been exercised in Bangladesh earlier for brickfields. Air quality models, such as Gaussian plume model, urban air shed model, box model and other trajectory and mesoscale models had been studying worldwide for many years. Dispersion model is being used to determine the location of an unknown emission source [4]. Concentrations of different pollutants for different seasons are also being measured by using an urban scale Gaussian dispersion model (ADMS-Urban) [5]. Industrial Source Complex Short Term (ISCST-3) model can be utilized to facilitate the study of emission source contributions to ambient concentrations of different pollutants [6]. Even in our neighboring countries such as India and Nepal, air pollution modeling has been used for different purposes. ISCST-3 model is being used to examine the assimilative capacity and the dispersion of pollutants in the different seasons due to industrial sources [7]. Apart from these, different other developed air quality models are being used for different purposes worldwide. So, introduction of an effective air pollution model to measure the pollution impacts from brick kiln in Bangladesh condition can be a breakthrough in improving the scenario. Our objective was to measure the pollutant from the brick kiln stacks at selected points on the ground level near the brickfields at different times during the dry season and to model air pollution caused by brickfields [8-9]. Industrial Source Complex (ISC) model version-3 (ISC3) was used for this study.

\section{EXPERIMENTAL}

Verification of the applicability of this model in Bangladesh especially for brickfield pollution was the main concern of this work. Different applications of that model can be utilized if it shows sufficient applicability in Bangladesh condition. After successful verification of this model, it was exercised to predict ambient air pollution loads under different circumstances which is discussed elsewhere [10]. Industrial Source Complex or ISC3 model was considered for the modeling purpose for this work. It was an EPA recommended air quality modeling software. Ground level concentrations of several pollutants were measured experimentally using different suitable equipments. These were also calculated using the ISC3 model. From the comparison of the experimental data and model generated data, performance of the air quality modeling software was ensured for both gaseous pollutants and Total Suspended Particulates (TSP).

\section{Site Selection}

For this work, a specific site near Dhaka was selected for observation. A cluster of brick fields having 41 brick kilns near Aminbazar bridge, was the site for observation. There are too many brickfields situated along the northern side of Dhaka and those have major impact on Dhaka city air quality compared to other brick kilns. As the wind direction in dry season is from north to south, observation site was selected in the northern side of Dhaka. All 41 stacks of this cluster had an average $130 \mathrm{ft}$ stack height and similar operating condition. The observation site is shown in a satellite image in Figures 1. In this figure, square blocks are the areas of each brick kiln.

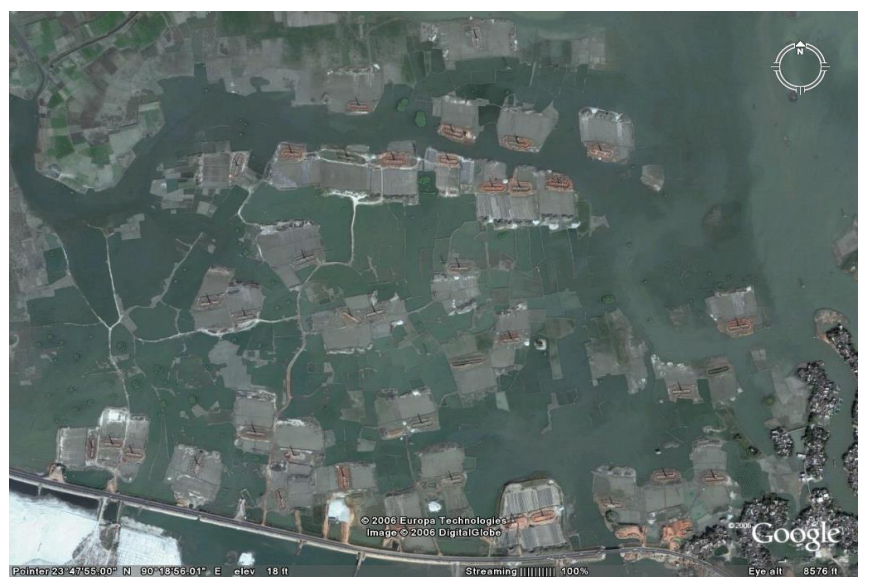

Figure 1: Satellite image of the cluster of brick kilns of the sampling site [10]

\section{Total Suspended Particulates (TSP) Measurement}

TSP was measured at the sampling sites by using a high volume sampler (Model No.: APM 415, Envirotech, India). It was for total particulate matter and includes both $\mathrm{PM}_{10}$ and $\mathrm{PM}_{2.5}$ of the ambient air. The sampler has it suction section at the top where a filter paper is placed in a filter holder. A pre-weighed and preconditioned EPM 200 $(8$ " $\times 10$ ") glass microfibre filter paper is placed on the netted flat surface which gives support to the paper.

During the operation, all the air sucked by the pump passes through the filter and moves toward the outlet. Thus all the suspended particulate materials are trapped in the filter paper. Detailed description of this apparatus is discussed somewhere else [10]. As there was no power source in the brickfield, it was powered by a portable $\mathrm{AC}$ source and was operated in the $1.0-1.3 \mathrm{~m}^{3} / \mathrm{min}$ flow range. One of the most important steps of sampling is the conditioning of the filter paper and that was done for 48 hours in silica gel desiccators before and after the measurement to ensure similar filter paper condition during weighing. It was operated for an average 6-8 hours each day and total air flow rate was calculated from the average air flow rate and total sampling time. From the difference in weight between the fresh and dusted filter paper, weight of total dust particle was calculated. 


\section{Gaseous Pollutant Measurement}

Gaseous pollutants, such as Carbon monoxide, Sulfur dioxide and lower hydrocarbon were measured at different location on different days using Standard Gastec tube system. The Gastec Standard Detector tube system mainly consists of the Model GV 100S Gas sampling pump and Gastec standard detector tubes. This system is capable of analyzing a wide variety of gases and vapors accurately, quickly and easily. Each tube contains detecting regents that are especially sensitive to the target substance and quickly produces a distinct layer of color change. For detecting lower class hydrocarbon, carbon monoxide and sulfur dioxide, model 103, Model 1L and model 5LC standard Gastec tube was used respectively. During Hydrocarbon measurement $\mathrm{SO}_{3}$ filter tube was used to traps $\mathrm{SO}_{3}$ to prevent it from entering sampling pump. Reactions involved in these tubes are shown below [10]:

$$
\mathrm{CO}+\mathrm{K}_{2} \mathrm{Pd}\left(\mathrm{SO}_{3}\right)_{2} \rightarrow \mathrm{Pd}+\mathrm{CO}_{2}+\mathrm{SO}_{2}+\mathrm{K}_{2} \mathrm{SO}_{3}
$$

Lower hydrocarbon $\left(\mathbf{C}_{2}-\mathbf{C}_{7}\right)+\mathrm{Cr}^{6+}+\mathrm{H}_{2} \mathrm{~S}_{2} \mathrm{O}_{7} \rightarrow \mathrm{Cr}^{3+}$

$$
\mathbf{S O}_{2}+\mathrm{I}_{2}+2 \mathrm{H}_{2} \mathrm{O} \rightarrow \mathrm{H}_{2} \mathrm{SO}_{4}+2 \mathrm{HI}
$$

\section{Description of the Model}

Air quality modeling is the mathematical simulation of how air pollutants spread in the ambient atmosphere. It is performed with computer programs that solve the mathematical equations and algorithms which simulate the pollutant dispersion. The dispersion models are used to estimate or to predict the downwind concentration of air pollutants emitted from sources such as industrial plants and vehicular traffic.

The Gaussian model is perhaps the oldest and the most commonly used model type. It assumes that the air pollutant dispersion has a Gaussian distribution, meaning that the pollutant distribution has a normal probability distribution. Gaussian models are most often used for predicting the dispersion of continuous, buoyant air pollution plumes originating from ground-level or elevated sources.

Gaussian plume idea is nothing but a material balance model. In it, one considers a point source such as a factory smokestack (which is not really a point but a small area that can be satisfactorily approximated as a point) and attempts to compute the downwind concentration resulting from this point source. The schematic representation and nomenclature are shown in Figure 2, where the origin of the coordinate system is placed at the base of the smokestack, with the $x$ axis aligned in the downwind direction. The contaminated gas stream, generally called a plume, rise a considerable distance above the smokestack because they are emitted at temperatures higher than atmospheric and with a vertical velocity and then leveling off to travel in the $x$ direction and spreading in the $y$ and $z$ directions as it travels.

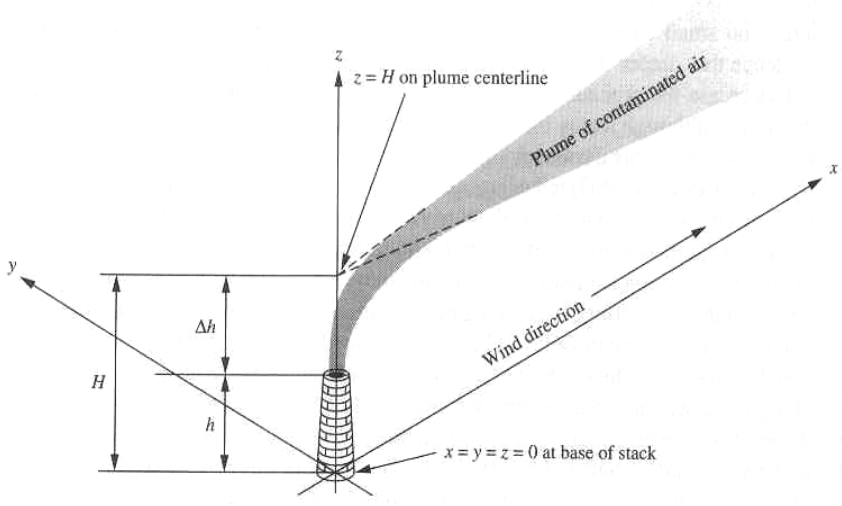

Figure 2: Coordinate system and nomenclature for the Gaussian plume idea [10]

For Gaussian plume calculations the plume is assumed to be emitted from a point with three dimensional coordinates $(0,0, \mathrm{H})$, where $\mathrm{H}$ is called the effective stack height, which is the sum of the physical stack height $(\mathrm{h})$ and the plume rise $(\Delta \mathrm{h})$. Gaussian equation representing concentration (C) at any location $\mathrm{x}, \mathrm{y}, \mathrm{z}$ is [9],

$$
C(x, y, z)=\frac{Q}{2 \pi u \sigma_{y} \sigma_{z}} \exp \left(-\frac{y^{2}}{2 \sigma_{y}^{2}}\right)\left[\exp \left(-\frac{(z-H)^{2}}{2 \sigma_{z}^{2}}\right)+\exp \left(-\frac{(z+H)^{2}}{2 \sigma_{z}^{2}}\right)\right]
$$

Where, point source is located at $0,0, \mathrm{H}$ that steadily emits a non-buoyant pollutant at emission rate $Q$ and the wind blows in the $x$ direction with velocity $u$ which is independent of time, location, or elevation. $\sigma$ represents the dispersion parameter or the standard deviation of the concentration in other two directions. Concentration profile of the Gaussian plume concept is shown in Figure 3.

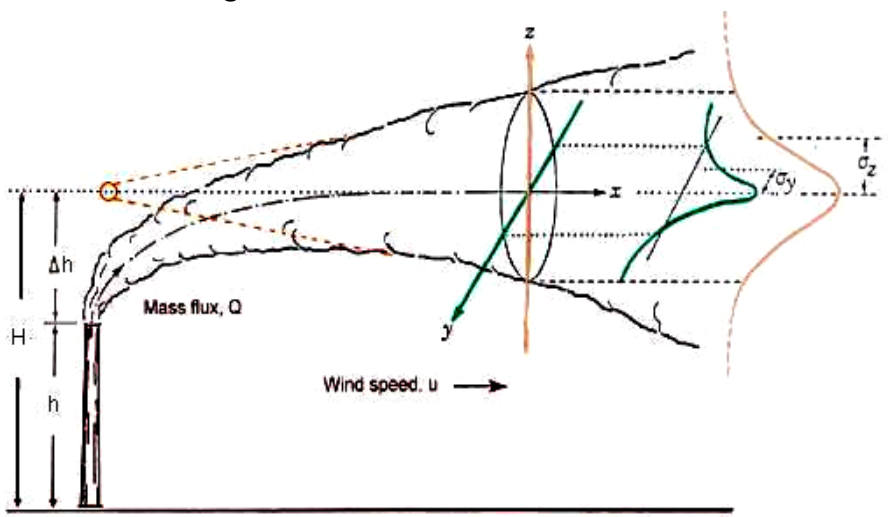

\section{Figure 3: Concentration profile of the Gaussian plume concept $[\mathbf{1 0}]$}

Gaussian plume model is based on few assumptions [9]. One of the major assumptions is that atmospheric stability and all other meteorological parameters are uniform and constant, and in particular that wind speed and direction are uniform and constant in the domain. 
Turbulent diffusion is a random activity and therefore the dilution of the pollutant can be described in both horizontal and vertical directions by the Gaussian distribution. Another important assumption is that the pollutant is released at a height above the ground that is given by the effective stack height $(\mathrm{H})$ and the degree of dilution is inversely proportional to the wind speed. It is also assumed that the pollutant is conservative.

\section{Model Setup}

There are two basic types of inputs that are needed to run the ISC models. They are (1) the input runstream file, and (2) the meteorological data file. The run stream setup file contains the selected modeling options, source information, receptor locations; meteorological data file specifications, and output options. These are assigned under five sub sections; Dispersion Options, Source Options, Receptor Options, Meteorology Options and Output Options. Typical source parameters used in the model are shown in Table 1.

\section{Table 1: Source parameters for the model*}

\begin{tabular}{|l|l|}
\hline Number of stack & 41 \\
Physical Stack height & $38 \mathrm{~m}$ \\
Stack exit diameter & $1 \mathrm{~m}$ \\
Stack exit velocity & $7.4 \mathrm{~m} / \mathrm{s}$ \\
Exit gas temperature & $335.43 \mathrm{k}$ \\
$\mathrm{SO}_{2}$ emission rate from each stack & $78.58 \mathrm{~g} / \mathrm{s}$ \\
$\mathrm{CO}$ emission rate from each stack & $1.108 \mathrm{~g} / \mathrm{s}$ \\
TSP emission rate from each stack & $44.22 \mathrm{~g} / \mathrm{s}$ \\
\hline * All the stacks were assumed to have same parameters
\end{tabular}

Meteorological data file contains all the required meteorological data on hourly basis. The major meteorological data that are necessary for the ISC3 model are ambient temperature, wind velocity and direction, mixing height. The Short Term model includes a dry deposition algorithm and a wet deposition algorithm. For these purposes some other data are also required such as MoninObukhov length, surface friction velocity, surface roughness and stability class. All those hourly data is preceded with the date and time. The wet deposition algorithm in the Short Term model also needs particle precipitation rate data. For this work all the meteorological data of our specified location were collected from World Meteorological Organization (WMO) data [11]. These are very much reliable and most of the models including climate models run on these data.

Before generating the input stream, the total observation area is to be divided into grids and expressed in terms of Cartesian coordinate system. Thus all the source locations and receptor positions can be defined with their coordinate values. The model generated values were the ambient concentrations at specified grid points based on previously defined coordinate system. Once a set of required files were run successfully, different output files were generated. These output files included the maximum concentrated areas, total model output and the coordinate based concentration data.

\section{RESULTS AND DISCUSSIONS}

Air sampling was done in the cluster of brickfields at different locations as shown in Figure 4 to verify the applicability of the Industrial Source Complex model (ISC3) in Bangladesh especially for brickfield emissions. A cluster of 41 brick kilns were considered which was situated to the north of Dhaka and very near to locality. In that cluster, all the stacks were assumed identical with the parameters mentioned in Table 1. Ambient pollutant concentrations at different locations were measured experimentally using Gastec tubes and High volume sampler on different days at two specified locations cluster as shown in Figure 1 and 4. Sampling on day 1 was done near the edge of the cluster and that on Day 2 and 3 were done at the centre of the brickfield cluster.

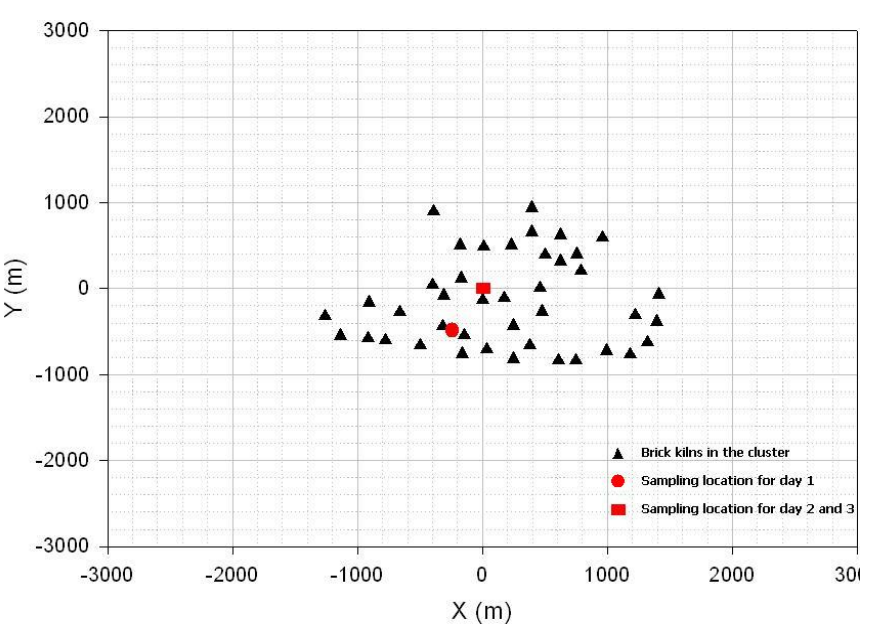

Figure 4: Sampling locations on the gridded observation site

The sampling data include the ambient concentration of Sulfur dioxide, Carbon monoxide and Total Suspended Particulates (TSP). Similar data were also generated through model to verify the acceptability of this model as shown in Table 2.

\section{Sulfur dioxide}

During the dry season experimental data for $\mathrm{SO}_{2}$, $\mathrm{CO}$, Hydrocarbon and Total Particulate Matter were collected on different days. From the 1-hr averaged experimental values of $\mathrm{SO}_{2}$ it was found that, the concentrations of ambient $\mathrm{SO}_{2}$ were more or less same for different days. Using the ISC3 
Table 2: Comparison of the experimental and modeling results

\begin{tabular}{|c|c|c|c|c|}
\hline Observation & $\begin{array}{l}\text { Pollu- } \\
\text { tants }\end{array}$ & $\begin{array}{l}\text { Averaging } \\
\text { time }\end{array}$ & $\begin{array}{l}\text { Modeled } \\
\text { value }\end{array}$ & $\begin{array}{l}\text { Sampling } \\
\text { value }\end{array}$ \\
\hline \multirow{5}{*}{$\begin{array}{c}\text { Day } 1 \\
24 / 02 / 2006 \\
\text { Sampling } \\
\text { point } 1\end{array}$} & \multirow{2}{*}{$\mathrm{SO}_{2}$} & $1 \mathrm{hr}$ avg. & & \multirow[t]{2}{*}{$0.05 \mathrm{ppm}$} \\
\hline & & $6 \mathrm{hr}$ avg. & $0.013 \mathrm{ppm}$ & \\
\hline & \multirow{2}{*}{$\mathrm{CO}$} & & $0.016 \mathrm{ppm}$ & \multirow{2}{*}{$2.5 \mathrm{ppm}$} \\
\hline & & $6 \mathrm{hr}$ avg. & $0.012 \mathrm{ppm}$ & \\
\hline & TSP & $6 \mathrm{hr}$ avg. & $\begin{array}{l}508.5 \\
\mu \mathrm{g} / \mathrm{m}^{3}\end{array}$ & $\begin{array}{l}780.72 \\
\mu \mathrm{g} / \mathrm{m}^{3}\end{array}$ \\
\hline \multirow{3}{*}{$\begin{array}{c}\text { Day } 2 \\
08 / 03 / 2006\end{array}$} & \multirow{2}{*}{$\mathrm{SO}_{2}$} & $1 \mathrm{hr}$ avg. & $0.1205 \mathrm{ppm}$ & \multirow{2}{*}{$0.06 \mathrm{ppm}$} \\
\hline & & $6 \mathrm{hr}$ avg. & $0.035 \mathrm{ppm}$ & \\
\hline & \multirow{2}{*}{$\mathrm{CO}$} & $1 \mathrm{hr}$ avg. & $0.032 \mathrm{ppm}$ & \multirow{2}{*}{$2.6 \mathrm{ppm}$} \\
\hline \multirow{2}{*}{$\begin{array}{l}\text { Sampling } \\
\text { point } 2\end{array}$} & & $6 \mathrm{hr}$ avg. & $0.016 \mathrm{ppm}$ & \\
\hline & TSP & $6 \mathrm{hr}$ avg. & $1338 \mu \mathrm{g} / \mathrm{m}^{3}$ & $\begin{array}{l}1389.8 \\
\mu \mathrm{g} / \mathrm{m}^{3}\end{array}$ \\
\hline \multirow{3}{*}{$\begin{array}{c}\text { Day } 3 \\
20 / 03 / 2006\end{array}$} & \multirow{2}{*}{$\mathrm{SO}_{2}$} & $1 \mathrm{hr}$ avg. & $0.09 \mathrm{ppm}$ & \multirow{2}{*}{$0.06 \mathrm{ppm}$} \\
\hline & & $6 \mathrm{hr}$ avg. & $0.03 \mathrm{ppm}$ & \\
\hline & \multirow{2}{*}{$\mathrm{CO}$} & $1 \mathrm{hr}$ avg. & $0.02 \mathrm{ppm}$ & \multirow{2}{*}{$2.8 \mathrm{ppm}$} \\
\hline Sampling & & $6 \mathrm{hr}$ avg. & $0.014 \mathrm{ppm}$ & \\
\hline point 2 & TSP & $6 \mathrm{hr}$ avg. & $652 \mu \mathrm{g} / \mathrm{m}^{3}$ & $\begin{array}{l}728.5 \\
\mu \mathrm{g} / \mathrm{m}^{3}\end{array}$ \\
\hline
\end{tabular}

model, concentrations of $\mathrm{SO}_{2}$ were found to vary within a certain range. Naturally, the lower time average values of those concentrations were found more than values generated with a higher time average. In general the experimental values varied from 0.05 to $0.06 \mathrm{ppm}$ whereas the modeling values varied from 0.044 to $0.12 \mathrm{ppm}$. This is shown through a comparative bar chart in Figure 5 with the Bangladesh standard value for $\mathrm{SO}_{2}$.

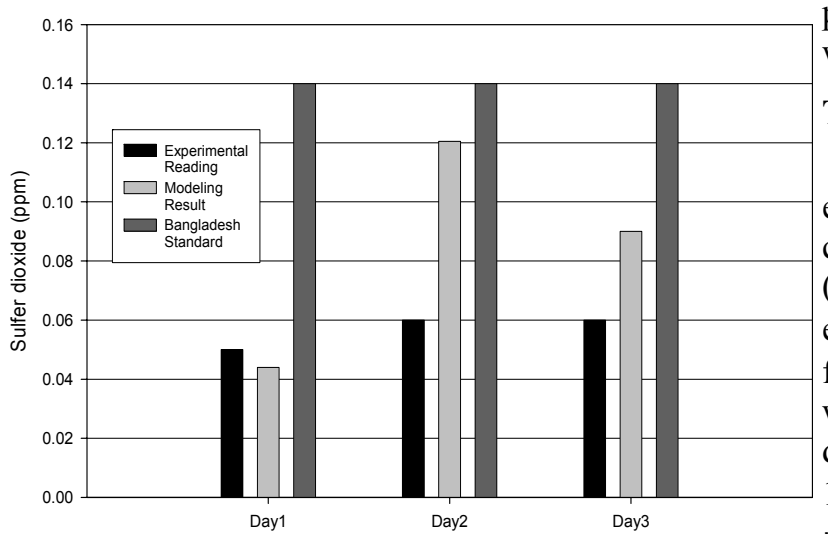

Figure 5: Comparison of different $\mathrm{SO}_{2}$ data

Ambient concentration of $\mathrm{SO}_{2}$ was found satisfactory according to that standard. Gastec tubes give the instantaneous concentration values and that can vary within a certain range depending on when the measurement was made. Moreover, as we know that the Gastec tube readings have some errors and don't give precise result, this modeling values can be considered acceptable for the large scale modeling. This negligible discrepancy in result will not affect much when this model would be used for long range modeling such as for one month or several months or year.

\section{Carbon monoxide}

When the concentrations of $\mathrm{CO}$ were considered, a significant difference between the experimental and modeling results was seen. Modeling results varied from $0.012-0.32 \mathrm{ppm}$ whereas experimental values varied from 2.5 to 2.8 ppm. This large discrepancy can probably be explained by considering the interferences of the transport vehicles moving around the sampling sites. As all the samplings were done within the brickfield areas and there were continuous movement of trucks around the sampling points carrying raw materials and bricks, the ambient concentrations were affected. Those vehicles exhausted substantial amount of pollutants into the atmosphere and $\mathrm{CO}$ is one of the major pollutant in that. Thus the concentration of ambient $\mathrm{CO}$ in the whole brickfield cluster area was generally higher compared to the normal ambient concentration of other places of the surroundings. Moreover pure ambient air itself contains $\mathrm{CO}$ up to $0.2 \mathrm{ppm}$. Here the modeling result was based on the brickfield stack emissions only but the experimental values were the combined effect of stacks and vehicles, thus making the $\mathrm{CO}$ concentration higher. Therefore, due to the lack of facility to do source apportionment of the ambient pollutant, it was not possible to determine the exact effect of the brick field sources. Considering the major interferences of the secondary pollution sources and the accuracy of results for other pollutants, it can be expected that modeling results of $\mathrm{CO}$ could be compared with the practical results if the secondary sources of pollution were absent.

\section{Total Suspended Particulates (TSP)}

Good agreement was found between experimental and modeling results of ambient concentrations of Total Suspended Particulates (TSP). On the first day, the 6-hr average experimental value was $781 \mu \mathrm{g} / \mathrm{m}^{3}$ whereas that from the modeling was $581 \mu \mathrm{g} / \mathrm{m}^{3}$. These values were found to be different for the second and third day. On the second day the experimental value was $1390 \mu \mathrm{g} / \mathrm{m}^{3}$ whereas the modeling result was 1338 $\mu \mathrm{g} / \mathrm{m}^{3}$ and on the third day the experimental value was $729 \mu \mathrm{g} / \mathrm{m}^{3}$ whereas the modeling result was $652 \mu \mathrm{g} / \mathrm{m}^{3}$. Like day 1 , all these data were calculated considering a 6 -hr averaging period. These results are shown in a comparative bar chart in Figure 6 along with the Bangladesh standard value for TSP. Ambient concentration of TSP was found quite higher according to that standard. Experimental data of the first day were collected at the edge of the brickfield cluster besides the road. Last two data were collected in the centre of the cluster where vehicle interference was less. So the 
last two values were quite near to the modeled values and the first experimental value was found little higher than the modeled value due to the dust contribution from the road.

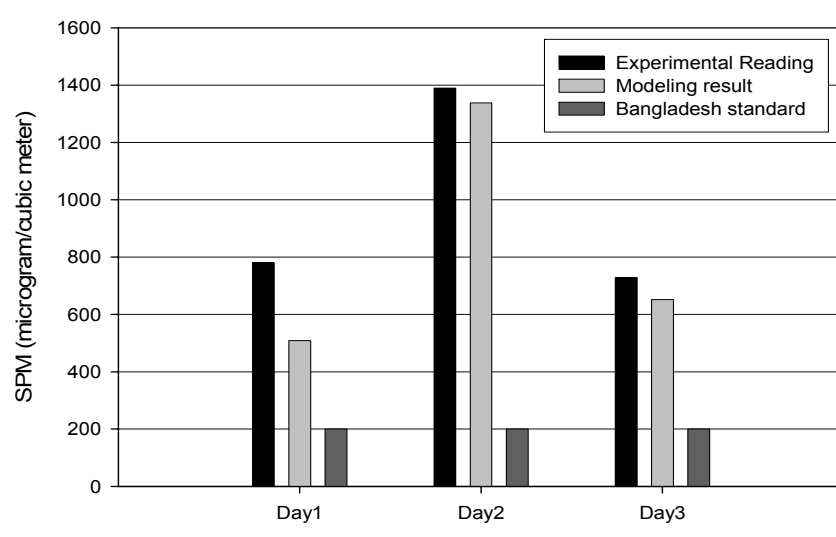

Figure 7: Comparison of different TSP data

However, in general it was quite satisfactory and this provides good evidence to strengthen the acceptability of the modeling software. It should be noted that though the last two data were collected at the same point but they had huge differences. This is because of the different meteorological conditions on these days. On the second day most of the time wind blew in such direction that pollutant from the most of the stacks transported towards the sampling point. So on that day the concentration value was found very high compared to the sampling data of the other day.

Apart from all these experimental errors, there might be some modeling errors. The meteorology data for the modeling were taken from the World Meteorological Organization which gives 6 hour interval values (i.e. only 4 data for a day). For simplicity of calculation, every one hour value was considered to be same for next five hours. However, in practice that is far from reality. Another possible reason for this discrepancy can be in the source emission data. Source data was taken from the earlier project report of the Chemical Engineering Department, BUET and considered to be same for all the brick kilns. It was also assumed that these sources emitted at the fixed rate constantly for total operating hours. However, practically this value is not same for all the kilns and no kiln deliver at a constant rate for the total operating period. As all of the kilns are operated by coal firing, the emission depends on coal charging time. When the fresh coal is charged there is an incomplete combustion due to lack of sufficient air to burn that coal. So during the coal charging time the emission rate is high and the flue gas looks black because it is full of carbon soot. After some time the combustion occurs with sufficient air and flue gas doesn't look black any more. So there is always a remarkable variation of flow rate and pollutant concentration during incomplete and complete combustion cycles. Since these are occurring in regular cycles of 20-30 minutes, the flow can be assumed to be fixed for the longer observation period. To make this more accurate, the source data was measured for three consecutive cycles and the average value was taken for modeling.

As discussed earlier, meteorological data and measurement methods along with some general simplified assumptions could be the sources of errors in the process of the verification of the accuracy of ISC3 model. Considering these probable errors and some measuring flaws, the Industrial Source Complex (ISC3) model can be considered as an acceptable one for Bangladesh, especially for brick kiln pollution modeling.

\section{CONCLUSION}

Applicability of Industrial Source Complex (ISC3) model near a cluster of brickfield has been verified successfully in this work. In spite of several limitations and possibilities of errors, ambient air quality data generated through ISC3 model were found to be in agreement with the experimental results. Negligible discrepancy between experimental values and modeling data was the strong evidence of the applicability of this model. Though U.S. Environmental Protection Agency (EPA) has already recommended it as one of the most effective models for ambient air quality modeling, the agreement found in this work supports their recommendation both for the gaseous pollutants and the particulate matters in brickfields. Percentage of error for modeling particulate matter was found $5-10 \%$ only on average. For gaseous pollutant percentage of error was little high but that was also acceptable considering the error margin of the Gastec tubes.

One of the most interesting observations of this study was the pollutant load within the cluster region for sulfur dioxide and particulate matters. It was found that the sulfur dioxide was not a major concern for these sources, as its concentration was far below the Bangladesh standard. However, particulate matter was a major pollutant in that region. Ambient concentration of particulate matters was way high compared to Bangladesh standard in every observation made in that region which should be taken care of immediately.

From the above data representations and discussions it is obvious that this type of models can be used as an effective tool for determining the effect of any pollution source prior to its establishment. That would certainly help the authority in issuing license for that establishment. More importantly, because of its ease of handling and availability, it can be utilized to revise the Environmental protection rules and regulations of any region for any hypothetical adverse situation. This can be utilized more in the wider arena of environmental analysis and can be proved to be a successful tool in air pollution analysis. 


\section{REFERENCES}

1. BPPW (Bangladesh Public Policy Watch), Dhaka city state environment report, 2003. The United Nations Environment Program (UNEP), 2005, published by Unnayan Onneshan -The Innovators.

2. UNEP (United Nations Environment Program), The Environment in the News. Monday, May 16 , 2005. http://www.unep.org/cpi/briefs/Brief2005May1 6.doc

3. Khaliquzzaman, M., Biswas, S. K., Tarafdar, S. A. and Islam, A., Paper presented at on, Air Pollution and Its Trend. in the Mid-Term Review Meeting 1999, Singapore, October 18-22.

4. Islam, M. A., Application of a Gaussian plume model to determine the location of an unknown emission source. Water Air Soil Pollution, 1999. 112: p. 241-245.

5. Owen, B., Edmunds, H. A., Carruthers, D. J., \& Singles, R. J., Prediction of total oxides of nitrogen and nitrogen dioxide concentrations in a large urban area using a new generation urban scale dispersion model with integral chemistry model. Atmospheric Environment, 1999. 34: p. 397- 406.

6. Hao, J., Wu, Y., Fu, L., He, D., \& He, K., Source contributions to ambient concentrations of $\mathrm{CO}$ and NOx in the urban area of Beijing.
Journal of the Environment Science and Health, 2001. 36: p. 215-228.

7. Krishna, R., Reddy,M. K., Reddy, R. C., \& Singh, R. N., Assimilative capacity and dispersion of pollutants due to industrial sources in Visakhapatnam bowl area. Atmospheric Environment, 2004. 38: p. 67756787.

8. Westbrook, J. A., Air Dispersion Models: Tools to Assess Impacts from Pollution Sources. Natural Resources \& Environment, 1999. 13(4): Spring 1999.

9. ESS (Environmental Software and Services), Air Quality Modeling in Environmental Impact Assessment. online lecture on air pollution and environmental impact assessment (AIR-EIA), 2002.

10. Ahmed, S., Modeling of Ambient Air Pollution in a Cluster of Brickfields, M.Sc. Engineering Thesis, 2007. Bangladesh University of Engineering and Technology, Dhaka, Bangladesh.

11. NOAA (National Oceanic and Atmospheric Administration) website based on World Meteorological Organization (WMO) data. http://www.cdc.noaa.gov/cdc/reanalysis/reanal ysis.shtm 